\title{
LAND SUBSIDENCE MONITORING IN DEZHOU CITY BASED ON SBAS-INSAR TECHNOLOGY
}

\author{
Guoman Huang ${ }^{1,2}$, Haitao Fan ${ }^{1,2}$, Lijun $\mathrm{Lu}^{2}$,Wenqing $\mathrm{Yu}^{1,2}$ \\ 1 Shandong University of Science and Technology, Qingdao, China - (fanhaitao666six, huang.guoman,w582305137)@163.com \\ 2 Key Laboratory of Surveying and Mapping Science and Geospatial Information Technology, Chinese Academy of Surveying and \\ Mapping, Beijing, China-lulj@casm.ac.cn
}

Commission III, WG III/3

KEYWORDS: Interferometric Synthetic Aperture Radar, Sentinel-1A, Small Baseline Subset, Dezhou, Land Subsidence Monitoring

\begin{abstract}
:
To monitor the large area land subsidence in Dezhou city, Shandong province, China. This paper uses 23 scenes of Sentinel-1A radar images from August 2017 to February 2019, and based on small baseline subset (SBAS) technology to obtain the subsidence information in Dezhou urban area. The monitoring results show that: Dezhou city has a serious subsidence phenomenon in large coverage area. A subsidence funnel with Chenzhuang as the center was formed. The average annual subsidence rate (along the vertical direction) of the subsidence center exceeded $45 \mathrm{~mm} / \mathrm{yr}$. There was also a serious subsidence phenomenon in the eastern and northeastern parts of the urban area, and there was a tendency of forming a whole area. After detailed data analysis, it is found that the ground subsidence presents seasonal characteristics closely related to the groundwater level and is affected by large-scale engineering construction on the surface.
\end{abstract}

\section{INTRODUCTION}

Land subsidence is a common environmental geological problem caused by many reasons, and it belongs to the slow type of geological disasters. The factors that cause ground subsidence can be divided into human factors and natural factors. Human factors mainly include the development and utilization of underground resources (groundwater, petroleum, mineral resources, etc.), and large-scale engineering construction. Natural factors mainly include earthquakes, volcanic activities, and the crust, movement etc. Land subsidence will cause serious harm to urban infrastructure, highway and railway transportation facilities, agricultural development, people's property and even life safety. Therefore, it is of great practical significance for real-time monitoring of land subsidence, mastering the mechanism of subsidence, predicting the future development trend of subsidence, and conducting research on prevention and control.

The traditional monitoring methods mainly include level measurement, GPS measurement, bedrock mark and layered mark measurement. Although the traditional measurement method has high accuracy, its measurement is mainly based on points, with a large workload and high cost. It is impossible to obtain deformation information of large scale planar region. With the rapid development of Interferometry synthetic aperture radar technology, with its large-scale, non-contact, all-weather, high-precision, low-cost advantages, it has effectively made up for the shortcomings of traditional monitoring technologies. It has been widely used in ground subsidence monitoring. Conventional D-InSAR is a technology that uses the phase information of radar images to obtain the surface deformation of the target area using differential interference processing of radar images of different phases in the same area. However, its monitoring accuracy is affected by time de-correlation, space de-correlation and atmospheric delay. Berardino et al.(2002) first proposed the SABS (Small Baseline Subset) technology, which is to set a certain time threshold and space threshold on the acquired long-term sequence of SAR images and combine them into several subsets. The least square method is used to reduce temporal and spatial decoherence, which could improve the coherence of the interferogram. The SVD (singular value decomposition) method is used to invert the ground deformation time series, which improves the utilization rate of SAR image data and the accuracy of the deformation monitoring results. In recent years, many researchers have used SBAS-InSAR technology for surface subsidence monitoring in different areas, proving that SBAS-InSAR technology has high accuracy and trial performance. $\mathrm{Hu}$ et al.(2019) applied PS-InSAR and SBAS-InSAR to generate surface deformation fields in Shenzhen and Hong Kong. Combined with GNSS, they found that there is clear settlement phenomenon in reclamation areas, especially in subway construction areas and buildings with shallow foundations. Lin et al.(2016) used multi-temporal SAR interferometry to monitor and characterize the temporal and spatial changes of ground deformation in Wuhan's major town area through the 12 sense of TerraSAR-X images acquired from 2009 to 2010, revealing the land subsidence information six major commercial and industrial areas in Wuhan. The maximum settlement rate is as high as $-67.3 \mathrm{~mm} / \mathrm{yr}$.

In recent years, the launch of multi-band, multi-polarization, and multi-band SAR satellites has greatly promoted the development and application of InSAR technology. The Sentinel-1 satellite launched by ESA in 2014 was equipped with C-band, multi-polarization, four working modes. With the advantages of short revisit cycle, especially free download, it provides a rich, long-term sequence of image data for

\footnotetext{
* Correspongding author Haitao Fan,E-mail adress:
} fanhaitao666six@163.com 
monitoring work, making it widely used in InSAR ground subsidence monitoring.

Three major ground subsidence zones have been formed in China, mainly the North China Plain, the Yangtze River Delta, and the Fenwei Basin. At present, Dezhou City, Shandong Province is mainly due to the continuous over-exploitation of groundwater and the large-scale engineering construction in the process of urbanization, which has caused serious ground subsidence. In this paper, 23 scenes of Sentinel-1A data is applied to monitor the ground subsidence in the urban area of Dezhou and its surrounding areas, to obtain the settlement location distribution and deformation rate, and to analyze the spatial distribution of settlement and the influencing factors leading to settlement.

\section{PRINCIPLES OF EXPERIMENTAL TECHNOLOGY}

Berardino et al.(2002) first proposed the SABS (Small Baseline Subset) technology, mainly uses the method of setting the spatial baseline threshold and the temporal baseline threshold to choose high-quality interferogram to reduce the influence of spatio-temporal decorrelation on interference.

Suppose that $\mathrm{N}+1$ scene of SAR images covering the same area are acquired at different times $\left(t_{1}, t_{2}, t_{3} \ldots\right)$, and a spatial baseline threshold is set for the $\mathrm{N}+1$ scenes of SAR image. The time baseline threshold is combined to form $\mathrm{M}$ differential interference patterns. The value range is:

$$
\frac{(N+1)}{2} \leq M \leq \frac{N(N+1)}{2}
$$

For the i-th interference pattern composed of the image acquired at $t_{1}$ time and the image acquired at $t_{2}$ time, the interference phase (ignoring the atmospheric delay phase, residual terrain phase, and noise phase) of a point on the interference image in equation (2):

$$
\delta_{\varphi_{i}}=\varphi_{2}-\varphi_{1}=\frac{4 \pi}{\lambda}\left(d_{2}-d_{1}\right)
$$

Where $\lambda$ is the wavelength of the radar, $d_{1}$ and $d_{2}$ are the cumulative deformation in the direction of the radar line of sight with respect to the time $t_{1}$, and the time $t_{2}$ respectively. Because there are $\mathrm{M}$ differential interferograms, we can get $\mathrm{M}$ equations according to equation 2 , and the $\mathrm{M}$ equations are represented by a matrix as:

$$
\varphi=\left(A^{T} A\right)^{-1} A^{T} \delta_{\varphi}
$$

In the formula, $\mathrm{A}$ is an $\mathrm{M} \times \mathrm{N}$ matrix, and its elements are composed of $-1,0$, and $1 . \delta_{\varphi}$ and $\varphi$ are Nth-order vector. When the images are only grouped, the rank of the matrix $\mathrm{A}$ at $\mathrm{M} \geq \mathrm{N}$ is $\mathrm{N}$ and the least square method is used to find the estimated value of $\varphi$.

$$
\delta_{\varphi}=A \varphi
$$

Otherwise, the matrix $\mathrm{A}^{\mathrm{T}} \mathrm{A}$ is a singular matrix, and the matrix is decomposed by the singular value decomposition method (SVD) to obtain the least-squares solution of the meaning of the minimum norm of the equation to obtain the cumulative deformation information. If the phase is directly solved using the SVD method, the deformation results are not continuous in time series, so it can be transformed into the average rate of the pixel points along the radar line of sight during the acquisition of adjacent images.

\section{EXPERIMENT AND ANALYSIS}

\subsection{Research area and experimental data}

Dezhou City is located in the plain of the middle and lower reaches of the Yellow River in North China. The terrain is flat. It is located in the northwest of Shandong Province. The basic climate is characterized by a significant monsoon effect, distinct four seasons, and clear boundaries between hot and cold and wet. The Cha River flows through the city center of Dezhou City. It divides the city into the economic development zone of Decheng District in the east and Decheng District in the west. The research area of this experimental area is mainly the urban area of Dezhou. Its geographical location is shown in Figure 1.

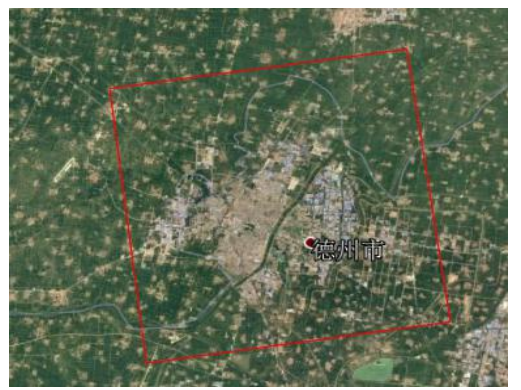

Figure 1. Scope of the experimental area

In this experiment, 23 scenes of Sentine-1A data from August 24, 2017 to February 27, 2019, covering the study area were applied, Sentinel-1A satellite carries C-band, the $5 \mathrm{~m} \times 20 \mathrm{~m}$ spatial resolution, VV polarization, IW mode, Precise Orbit Ephemerides provided by ESA for each image, and SRTM3DEM data with a resolution of $90 \mathrm{~m}$ to remove the terrain phase. Table 2 is the image parameter information of Sentinel-1.

Sentinel-1 satellite consists of two satellites developed by the European Commission and ESA for the Copernicus Global Earth Observation Project satellite constellation, mainly used for marine environment monitoring and Arctic sea ice monitoring, marine oil spill and ship monitoring, surface deformation monitoring, water management and soil protection, forest fire monitoring, etc. The Sentinel satellite has four modes of operation: strip map (SM), interferometric wide swath (IW), wave (WV), and extra wide swath (EW). The main design parameters of each mode are shown in table 1. IW is the primary mode of operation, as well patterns used for surface settlement monitoring.

\begin{tabular}{ccccc}
\hline $\begin{array}{c}\text { Work } \\
\text { mode }\end{array}$ & $\begin{array}{c}\text { Width } \\
/ \mathrm{km}\end{array}$ & $\begin{array}{c}\text { Angle of } \\
\text { incidence/ } \\
\left({ }^{\circ}\right)\end{array}$ & $\begin{array}{c}\text { Spatial } \\
\text { resolution/m }\end{array}$ & $\begin{array}{c}\text { Polarization } \\
\text { mode }\end{array}$ \\
\hline IW & 250 & $29.1 \sim 46$ & $5 \times 20$ & $\begin{array}{c}\text { HH+HV,VV+ } \\
\text { VH,HH,VV }\end{array}$ \\
SM & 80 & $18.3 \sim 46.8$ & $5 \times 5$ & $\begin{array}{c}\mathrm{HH}+\mathrm{HV}, \mathrm{VV}+ \\
\mathrm{VH}, \mathrm{HH}, \mathrm{VV}\end{array}$ \\
WV & $20 \times 20$ & $\begin{array}{c}21.6 \sim 25.1 \\
34.8 \sim 38\end{array}$ & $5 \times 5$ & $\mathrm{HH}, \mathrm{VV}$ \\
& & $\begin{array}{c}18.9 \sim 47 \\
\text { EW }\end{array} 400$ & $20 \times 40$ & $\begin{array}{c}\mathrm{HH}+\mathrm{HV}, \mathrm{VV}+ \\
\mathrm{VH}, \mathrm{HH}, \mathrm{VV}\end{array}$ \\
\hline
\end{tabular}

Table 1. Main parameters of Sentinel-1 satellite 


\begin{tabular}{ccccccc}
\hline ImagelD & Date & Satellite platform & Polarization & Track & $\begin{array}{l}\text { Time baseline } \\
\text { /day }\end{array}$ & $\begin{array}{c}\text { Baseline } \\
\text { length/m }\end{array}$ \\
\hline 1 & 2017.08 .24 & Sentinel-1A & VV & descending & -168 & 78.0322 \\
2 & 2017.09 .17 & Sentinel-1A & VV & descending & -144 & 12.9569 \\
3 & 2017.10 .11 & Sentinel-1A & VV & descending & -120 & -53.8 \\
4 & 2017.10 .23 & Sentinel-1A & VV & descending & -108 & 16.993 \\
5 & 2017.11 .04 & Sentinel-1A & VV & descending & -96 & 104.228 \\
6 & 2017.11 .28 & Sentinel-1A & VV & descending & -72 & 8.50951 \\
7 & 2017.12 .21 & Sentinel-1A & VV & descending & -48 & 141.538 \\
8 & 2018.01 .27 & Sentinel-1A & VV & descending & -12 & 59.7751 \\
9 & 2018.02 .08 & Sentinel-1A & VV & descending & 0 & 0 \\
10 & 2018.03 .04 & Sentinel-1A & VV & descending & 24 & 29.9294 \\
11 & 2018.05 .03 & Sentinel-1A & VV & descending & 60 & 84.6739 \\
12 & 2018.05 .27 & Sentinel-1A & VV & descending & 84 & 7.96817 \\
13 & 2018.06 .08 & Sentinel-1A & VV & descending & 96 & -1.29883 \\
14 & 2018.07 .26 & Sentinel-1A & VV & descending & 144 & 70.9244 \\
15 & 2018.08 .07 & Sentinel-1A & VV & descending & 156 & 27.0811 \\
16 & 2018.09 .24 & Sentinel-1A & VV & descending & 204 & 90.0649 \\
17 & 2018.10 .18 & Sentinel-1A & VV & descending & 228 & -52.1213 \\
18 & 2018.11 .23 & Sentinel-1A & VV & descending & 264 & 129.207 \\
19 & 2018.12 .05 & Sentinel-1A & VV & descending & 276 & 88.2284 \\
20 & 2018.12 .17 & Sentinel-1A & VV & descending & 288 & 86.5157 \\
21 & 2019.01 .10 & Sentinel-1A & VV & descending & 312 & 58.6208 \\
22 & 2019.02 .03 & Sentinel-1A & VV & descending & 336 & 85.7148 \\
23 & 2019.02 .27 & Sentinel-1A & VV & descending & 360 & -25.0816 \\
& & & & & & \\
\hline
\end{tabular}

Table 2 . The image parameter information of Sentinel-1A

\subsection{Data processing}

(1) Set thresholds for 23 cropped Sentinel-1A image data for interference and combination processing. Since the experimental area is mainly an urban area, it is less affected by time decorrelation. The time baseline is set to $120 \mathrm{~d}$. View the interferogram of each image pair in turn, and then remove the interference image pairs with low coherence. We get 89 interfergrams. The combination of interference pairs is shown in Figure 2.The time baseline of interference pair combination is shown in Figure 3.

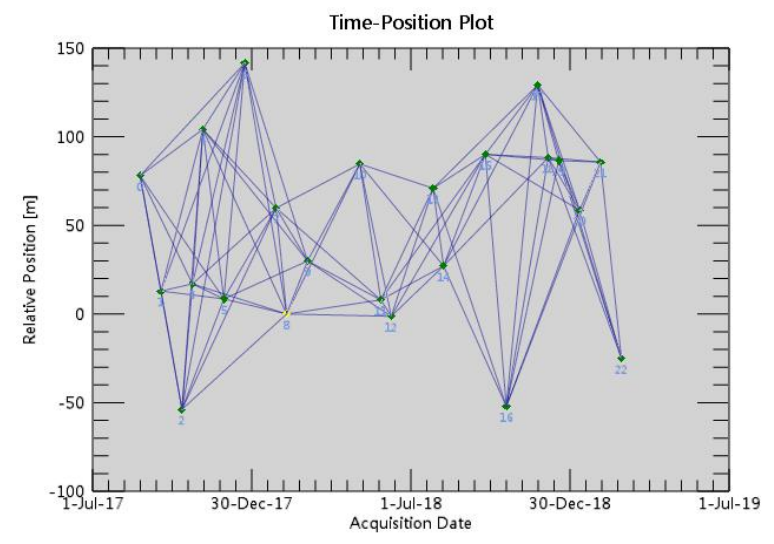

Figure 2. Interference pair combination

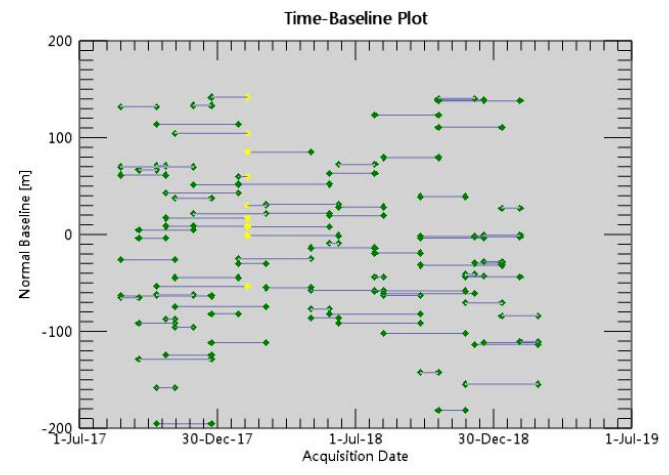

Figure 3. The time baseline of interferogram

(2) Perform conventional interference processing on all sets of interference images, including: Interferogram Generation, Interferogram Flattening, Filter and Coherence Generation, Phase Unwrapping. The SAR image is first registered to the same coordinate space, and the two images are multiplied by complex conjugates. Then the SRTM3-DEM data is used to remove flat phase. In order to reduce the noise of the interferogram and increase the signal-to-noise ratio, the interferogram is subjected to Goldstein filtering. For phase unwrapping, a minimum cost flow (MCF) based on Delaunany triangulation is used, and the coherence threshold in the phase unwrapping is set to 0.35 to suppress the influence of noise errors and low coherence points on the unwrapping effect.

(3) After unwrapping, select GCP control points to remove residual constant phase and phase ramp in areas without residual terrain stripes, deformation stripes, and phase jumps. The singular value decomposition method was used to estimate the deformation rate and residual terrain of the high coherence points, and then the secondary unwrapping was performed to 
further optimize the interference graphical entanglement results. Atmospheric time-domain high-pass filtering and spatialdomain low-pass filtering are performed on the results of the secondary unwrapping to remove the atmospheric phase. Finally, geocoding was performed to obtain the average annual deformation rate in the experimental area. The specific data processing flow is shown in Figure 3 .

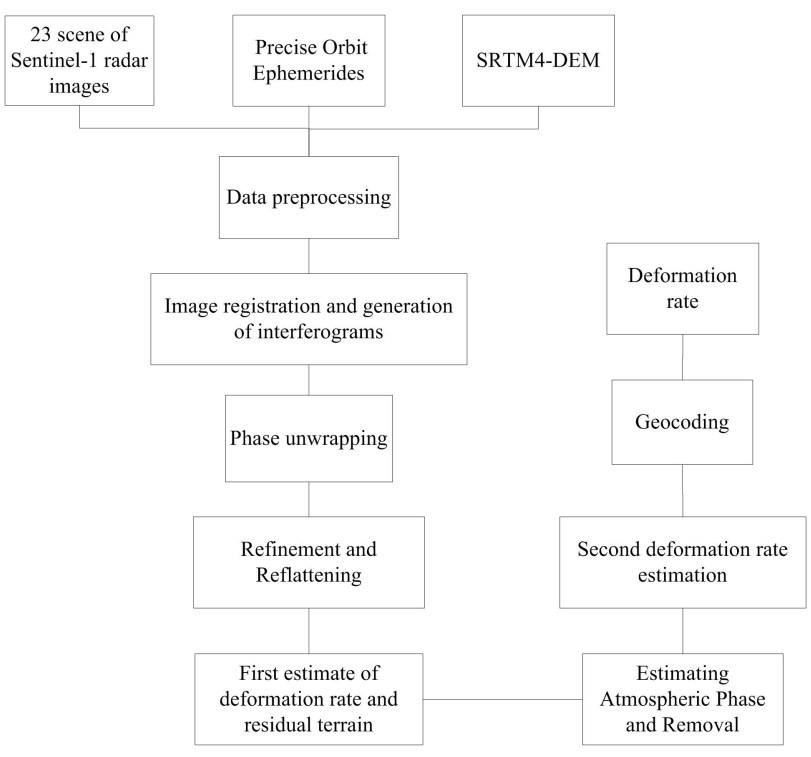

Figure 3. Data Processing Process

\subsection{Result analysis}

In this experiment, the surface subsidence of Dezhou city and surrounding areas was monitored from August 2017 to February 2019. The annual average deformation rate (along the vertical direction) is shown in Figure 4, and the statistical histogram of the annual average deformation rate is shown in Figure 5. It can be seen from:

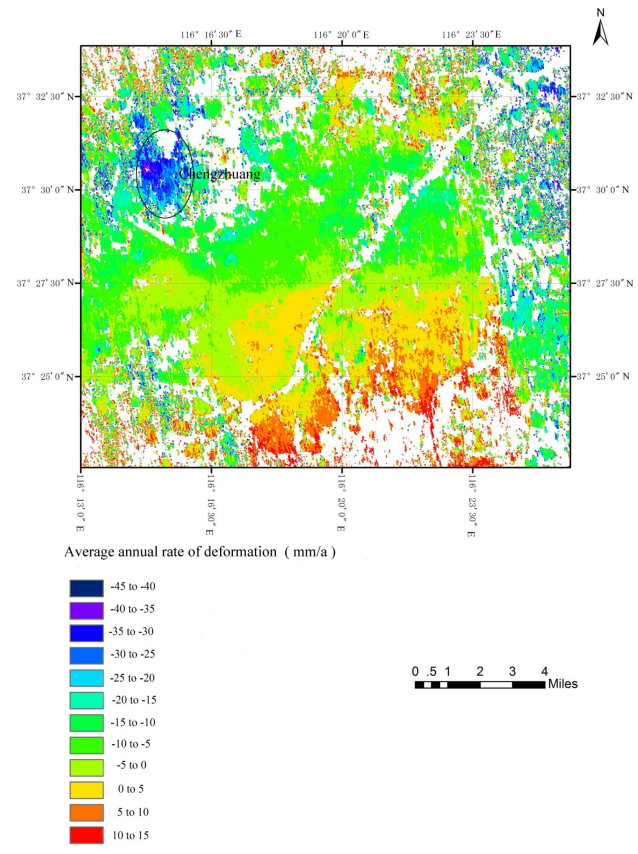

Figure 4. Annual average rate of deformation in urban areas of Dezhou City

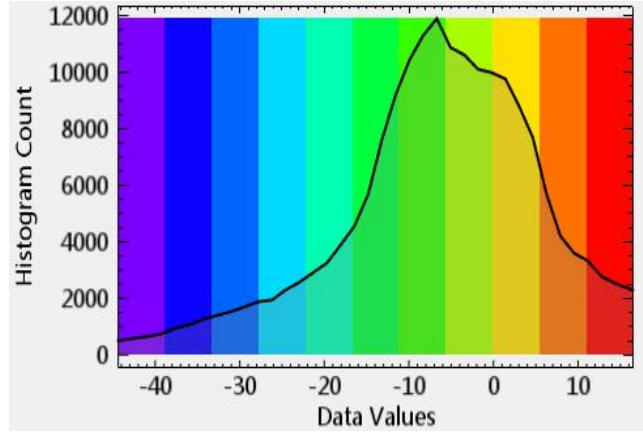

Figure 5. Annual average deformation rate value statistical histogram

(1) The average surface deformation rate (along the vertical direction) of Decheng district, Dezhou city during the monitoring period from August 2017 to February 2019 is mainly concentrated in the range of $-20 \sim 10 \mathrm{~mm} / \mathrm{yr}$. Positive values represent surface rise and negative values represent surface subsidence. Surface subsidence occurred in about $70 \%$ of the area, and the surface subsidence phenomenon is very obvious. The regional subsidence rate is mainly concentrated in the range of $-20 \sim 0 \mathrm{~mm} / \mathrm{yr}$, and the annual average maximum subsidence rate is in the area near Chenzhuang, reaching -45 $\mathrm{mm} / \mathrm{yr}$.

(2) An obvious settling funnel is formed centered on Chenzhuang, with a large settling rate. The settlement rate is above $-33 \mathrm{~mm} / \mathrm{yr}$, the settlement rate of Chenzhuang center is more than $-45 \mathrm{~mm} / \mathrm{yr}$. Subsidence areas in the eastern and northeastern regions of the urban area have become a new area with severe subsidence in recent years.

(3) The settlement range is large, the scope is wide, and is not uniform. Compared with the data published before, although the ground settlement center is basically stable, the settlement funnel scope keeps expanding, and the cumulative settlement increases, which is of great harm.

\section{CAUSE ANALYSIS}

Land subsidence is a slow geological disaster caused by many factors. The main causes of land subsidence in Dezhou are as follows:

(1) Groundwater exploitation: The continuous over-exploitation of groundwater caused by the use of urban residents water, industrial water, and agricultural water around the urban area in Decheng District is the main cause of land subsidence in Dezhou. Take the Chenzhuang funnel as an example, many chemical, material, textile, and other water-intensive enterprises gather here. It is an old industrial base in Dezhou. It consumes a lot of groundwater, which causes the adjustment of the stress of each stratum, triggers the compression of each stratum. The deformation history map of Chenzhuang in the settlement funnel center during the monitoring period from August 2017 to February 2019 is drawn, as shown in Figure 6, showing the overall settlement trend. From January to May, there is little rainfall in the spring. Dezhou is in the North China Plain and its agriculture is developed. The main crop is wheat, which requires a lot of groundwater for irrigation. In the summer months from June to August, rainfall increased, agricultural water use decreased, groundwater levels rose, and subsidence rebounded. Land subsidence is closely related to the groundwater level and presents seasonally related non-linear fluctuations.

(2) Urban engineering construction: With the progress of urbanization, the density and weight of ground buildings have 
increased significantly, increasing the surface load. The impact of urban ground load on land subsidence is obvious in the eastern economic development zone. In order to make the urban planning more reasonable, Dezhou City proposed the eastward goal: "Build a" modern and livable modern city ", that is, vigorously develop and construct in the eastern part of the city, and build a modern new city. 35 large-scale urban construction projects in 2017 start-up, development of underground space, excavation of foundation pits of high-rise buildings, increased surface loads, failure of rock and soil physical balance, and accelerated ground subsidence. Due to the uneven spatial distribution of engineering construction projects and engineering differences, there are differences in settlements in different regions.

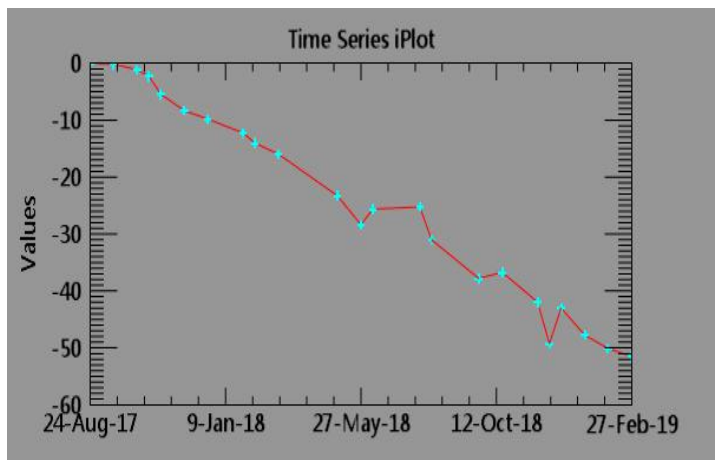

Figure 6. Chenzhuang funnel transformation history

At present, the continuous subsidence of the ground in Dezhou City has restricted economic development, posing a threat to people's production and life. Based on the analysis of the causes of ground subsidence, make suggestions and policies to deal with the ground subsidence, such as strictly controlling the amount of groundwater extraction, scientifically and rationally extracting groundwater, artificially recharging the groundwater periodically, evaluating and predicting the ground subsidence that may be induced by construction projects, and controlling construction project scale to reduce ground load.

\section{CONCLUSION}

In this paper, 23 scenes of Sentinel-1A radar images covering the urban area of Dezhou city from August 2017 to February 2019 were used for interference processing using SBAS technology. The land subsidence information of Dezhou city is obtained, and the distribution range, rate, inducement and prevention measures of land surface subsidence are analyzed and studied. The results show:

(1) There is a wide range of ground settlement in the urban area of Dezhou city, and the settlement rate is mainly concentrated in the range of $-20 \sim 0 \mathrm{~mm} / \mathrm{yr}$, and a significant settlement funnel centered on Chenzhuang is formed, with the annual average settlement rate exceeding $45 \mathrm{~mm} / \mathrm{yr}$. In the eastern and northeastern urban areas with intensive construction, nonuniform contiguous settlement areas are formed.

(2) Continuous over-exploitation of deep groundwater is the main cause of land subsidence in Dezhou, and large-scale surface engineering construction also aggravates land subsidence.

(3) Relevant departments should combine leveling, GPS, bedrock mark and stratification mark measurement and InSAR technology to strengthen the monitoring of land subsidence and improve the monitoring system, for the purpose of the monitoring and prevention of land subsidence.
(4) Lack of measured data, no settlement monitoring result accuracy evaluation. In the follow-up study, the ground subsidence is further explored by combining the measured data and geology.

\section{ACKNOWLEDGEMENTS}

The authors would like to thank European Space Agency (ESA) for providing Sentinel data and National Aeronautics and Space Administration (NASA) for providing SRTM-4DEM data.And the authors would like to thank the collaboration, support of the National Key Research and Development Program of China, (No.2018YFF0215303 and 2017YFB0503004).

\section{REFERENCE}

Berardino, P., Fornaro, G., Lanari, R., 2003. A new algorithm for deformation monitoring based on small baseline differential SAR interferograms. IEEE Transactions on Geoscience \& Remote Sensing, 42(7): 1377-1386.

Federica, M., Christian, B., Carlo A. B. \& Luca, P., 2019. Ground Deformations Controlled by Hidden Faults: MultiFrequency and Multitemporal InSAR Techniques for Urban Hazard Monitoring. Remote Sensing, 11(19).

Giuseppe, C., Cristiano, T., Carlo A. B., et al., 2018. Landslides and Subsidence Assessment in the Crati Valley (Southern Italy) Using InSAR Data. Geosciences, 8(2).

Gao, E.T., Fan, D.L., Fu, B.L., Yong, Q., Lan Y.P., 2019. Monitoring of Land Subsidence in Nanjing Based on PS-InSAR and SBAS Technology. Journal of Geodesy and Geodynamics, 39 (02): $158-163$.

Hu, B.; Chen, J.Y.; Zhang, X.F., 2019. Monitoring the Land Subsidence Area in a Coastal Urban Area with InSAR and GNSS. Sensors., 19, (14).

Hasan, R., Hossein, J., Saeed, K, N., 2019. Mohammad Ranjbar. Seven years of surface deformation above the buried Nasr-Abad salt diapir using InSAR time-series analysis, Central Iran. Journal of Geodynamics, 130.

Lin, B.; Jiang, L.M., Wang, H.S., Sun, Q.S., 2016. Spatiotemporal Characterization of Land Subsidence and Uplift (2009 - 2010) over Wuhan in Central China Revealed by TerraSAR-X InSAR Analysis. Remote Sensing, 8(4).

Mao, Y., Xiang, M., Han, Y., \& Gao, W., 2013. Weighted joint calibration for interferometric SAR. Journal of Systems Engineering and Electronics, 24(5), 761-771.

R, S., R K., 2019. Modeling Land Subsidence Using InSAR and Airborne Electromagnetic Data. Water Resources Research, $55(4)$.

Stephen, G., Elmira, O., Andrew, S., David, G., Ahmed, A., 2019. Delineating ground deformation over the Tengiz oil field, Kazakhstan, using the Intermittent SBAS (ISBAS) DInSAR algorithm. International Journal of Applied Earth Observations and Geoinformation, 81 .

Wang, Q.J.,Yu, W.Y., Xu, B., Wei, G.G. 2019. Assessing the Use of GACOS Products for SBAS-InSAR Deformation 
Monitoring: A Case in Southern California. Sensors (Basel, Switzerland), 19(18).

Wang, Z.Y., Zhang, J.X., Huang, G.M., 2014. Fine monitoring and analysis of Jining mining area settlement based on InSAR. Journal of China University of Mining \& Technology, 43 (01): 169-174.

Xiao, R.Y., He, X.F., 2019. Application of time series InSAR reservoir deformation monitoring. Journal of Wuhan University (Information Science Edition), 44 (09): 1334-1341.

Zhu, J.J., Li, Z.W., Hu, J., 2017. InSAR deformation monitoring methods and research progress. Journal of Surveying and Mapping, 46 (10): 1717-1733.

Zhang, Y.M., Wang, P., Luo, X., Zhang, B., Chen, H., 2017. Using Sentinel-1 data and SBAS-InSAR technology to monitor surface subsidence in Xi'an. Bulletin of Surveying and Mapping, (04): 93-97.

Zhou, Z.W., Xi, Z.P., Liu, S., Li, Z.H., 2011. Application of Permanent Scatterer and Short Baseline Radar Interferometry to Urban Surface Deformation. Geomatics and Information Science of Wuhan University, 36 (08): 928-931. 